\title{
First Aid Knowledge and Attitude of Secondary School Students in Saudi Arabia
}

\author{
Ali S. Mobarak' ${ }^{1}$ Raouf M. Afifi ${ }^{2,3^{*}}$, Amani Qulali ${ }^{3}$ \\ ${ }^{1}$ Emergency Department, Prince Mansour Hospital, Taif, Kingdom of Saudi Arabia \\ ${ }^{2}$ Academic Consultancy, Board of Family and Community Medicine Program, Taif, \\ Kingdom of Saudi Arabia \\ ${ }^{3}$ Community Health Institute, International Management-Health Services Inc., Indianapolis, IN, USA \\ Email: raoufafifi@hotmail.com
}

Received 6 September 2015; accepted 26 October 2015; published 29 October 2015

Copyright (C) 2015 by authors and Scientific Research Publishing Inc.

This work is licensed under the Creative Commons Attribution International License (CC BY). http://creativecommons.org/licenses/by/4.0/

(c) (i) Open Access

\begin{abstract}
Background: Increasing the number of qualified people, including school students who can play a significant role in first-aid (FA) and basic life support (BLS) arena is a public health demand. Aim: To assess the awareness of Saudi secondary school students regarding FA and BLS. Methodology: 360 male secondary school children in Taif, Saudi Arabia were surveyed. Results: The mean students' age was $17.4 \pm 1.21$ years. The mean participants' FA knowledge score was $64.8 \% \pm 11 \%$. Generally, trained students reported both better FA knowledge and skills than untrained counterparts; for $79.6 \%$ trained-compared to $53.7 \%$ untrained-students recorded such score $>70 \%\left[\chi^{2}\right.$ (df 1) $=11.60, p<0.001]$. The younger the age was, the higher opportunity to record a high score $(>70 \%)\left[62.3 \%<17\right.$ y vs. $49.3 \% \geq 17$ y, $\left.\chi^{2}(\mathrm{df} 1)=5.90, p=0.02\right]$ was. Trained students better deal with critical cases, bleeding and bodily injury compared to untrained peers $\left[89.8 \%\right.$ vs. $55.9 \%, \chi^{2}(\mathrm{df}$ 1) $=20.3, p<0.001 ; 83.7 \%$ vs. $58.2 \%, \chi^{2}$ (df 1$)=11.62, p=0.04 ; 81.6 \%$ vs. $67.2 \%, \chi^{2}$ (df 1$)=4.13, p=$ 0.04 , respectively]. Only $37.2 \%$ of schools had FA incorporated in the education curriculum. Eventually, FA training and the presence of FA group were significant predictors for improved FA knowledge among students [odds ratio (OR) 3.35, 95\% CI 1.60 - 7.06; 0R 2.28, 95\% CI 1.34 - 3.95, respectively). Conclusions: First-aid training is crucial to enhance school children's FA skills and to thrust their contribution to health emergency control efforts. Incorporating FA training within the educational curriculum of Saudi schools is a step forward to disseminate FA message in the community.
\end{abstract}

\section{Keywords}

First Aid, Secondary-School, Students, Saudi Arabia

\footnotetext{
*Corresponding author.
} 


\section{Introduction}

First aid is the provision of limited care for an illness or injury, which could be provided, usually by a lay person, to a sick or injured patient until definitive medical treatment can be accessed, or until the illness or injury is dealt with (as not all illnesses or injuries will require a higher level of treatment) [1]. It generally consists of series of simple, sometimes life saving, medical techniques, which an individual, either with or without formal medical background can be trained to perform with minimal equipment. First aid applies to a broad range of medical situations and consists both of specific knowledge and skills (e.g., what to do for each type of injury or illness) and the ability to assess a situation and make appropriate decisions, (such as when to call for emergency medical assistance) [2]. There is also a broad category in which FA literally means providing the FA, e.g., initiating a procedure such as cardio-pulmonary resuscitation (CPR) or defibrillation for a heart attack, which will be taken over by medical professionals as soon as they become available. This is classic FA [3]. Much of FA is a common sense, and people are almost certain to learn some elements as they go through their life, (e.g., knowing to apply an adhesive bandage to a small cut on a finger) [4]. However, effective life-saving FA requires hands-on training by experts, especially where it relates to potentially fatal illnesses and injuries, such as those requiring $\mathrm{CPR}$, as the procedures may be invasive and bring a risk of further injury to the patient [5]. A FA kit is a collection of supplies and a variety of equipment that may include bandages for controlling bleeding, personal protective equipment (PPE) such as gloves, a breathing barrier for performing rescue breathing, and sometimes instructions on how to perform first aid [6]. Knowledge of FA measures is important for every individual at every age, including school children [7]. In the developed countries, people are learned to call specific numbers, e.g., 911 in the USA, however the situation is different in many developing countries where awareness of the community is not as appropriate. Because children spend considerable time at school when they are not with their families, situations requiring FA often are encountered out there. The educational environment at schools facilitates teaching and training in different topics such as FA. Further, students represent good source of information that can be transformed to the community. Therefore, many studies have emphasized that teaching basic FA should be compulsory in all schools [8] [9]. The issue is that school children are highly exposed to emergency situations because of increasing activity. Particularly adolescents and secondary school-age students (equivalent to high school) are at greater risk of emergency situations and accident incidents with the severest consequences [10] [11], perhaps due to an increased tendency of involvement into riskier physical behavior and strenuous violent acts. Historically, FA training of voluntary laypersons was introduced in England about 120 years ago. At that time, like today, the purpose of the training was to teach life-saving techniques that would help avoid worsening of the situation for an injured person, and to facilitate future recovery [12]. Early FA may have a secondary, preventive effect although it does not prevent crashes or strokes; in some cases, it may alleviate the consequences of the these emergencies [13].

The precious time saved onsite: Undoubtedly, assistance given during the first few minutes after a crash often is of great importance for those who are injured, especially in terms of future health and quality of life [14]. A considerable amount of time may pass before an ambulance and professional rescue personnel arrives. Thus, it is imperative that bystanders have both the confidence and the knowledge to correctly administer first aid to the victims [15]. Without prompt life-saving assistance, an injured person may die for a number of reasons, such as airway obstruction or other causes correlated to pre-hospital death following trauma [16]. At some of the emergency sites, no FA is given because none of the bystanders could or wanted to provide such assistance. This means that a number of critical cases did not receive the help they needed, e.g., because bystanders had inadequate knowledge of emergency care [17]. On the other hand, bystanders may hesitate to offer FA due to insufficient knowledge or the fear of making things worse and believing that an ambulance will arrive soon, or that apprehensions may become manifest that they will be exposed to agents that cause infectious diseases, such as human immunodeficiency virus (HIV) [18].

Importance of training the skills of first aid: It is ascertained that properly administered FA-restoration of upper respiratory tract patency, pulmonary-circulatory resuscitation, massive internal bleeding arrest, placement of the victim in safe position - may save the lives of many victims of accidents. It is crucial that everybody should know FA principles and administer it before paramedics arrive [19]. As it was proven that for most causes of sudden unexpected death, a bystander's ability and willingness to perform CPR will increase the chance of the victim's survival. For out-of-hospital cardiac arrest, bystander CPR increases the likelihood of survival two to three times [20], and for drowning, CPR may be all that is required to resuscitate the victim. The bystander 
CPR in first minutes after cardiac arrest appears to be a crucial component of the chain of survival because failure of the circulation for 5 - 6 minutes will lead to irreversible cerebral damage and death [21]. Training of life-sup-porting first-aid (LSFA) in the undergraduate phase might prove a useful means of increasing cardiac arrest survival rates. In a study from Austria, it was found that training is a feasible proposition for as young as 9 12-year olds who might well be in a position to save the lives of cardiac-arrest victims. And it was recommended that future training sessions should determine the impact of repeated courses and the findings should be used to convince politicians and administrators of the need of LSFA training as a mandatory subject in schools [22].

Scholastic curricula and students' knowledge about first aid: Life-threatening emergencies can occur in any school, at any time. They can be caused by injuries, violence, pre-existing health problems, and other unexpected events. They can affect students or the adults who teach and supervise them. At the same time, schools now employ no nurses, leaving teachers, and other staff in charge of first aid before the arrival of emergency medical services personnel. It has been calculated that, on average, $20 \%$ of the population should be trained to provide FA, if a significant reduction of mortality is to be achieved. However, wide dissemination of the principles of emergency care poses a series of difficulties [23]. Many studies have been carried out on FA knowledge and attitude among secondary school students. Goniewicz, et al. [19] have conducted a study on 642 Polish high school children in 2002. Only 21\% could undertake FA procedures at accident site, and as much as $67 \%$ admitted that their FA skills were insufficient. On the other hand, most (80\%) children knew how important FA was. Eventually, the study recommended that training should start in primary schools and continue in adult life and in the place of work. And it was recommended that FA training should be conducted by physicians using the most modern educative devices. Working on the same FA knowledge area, Sosada, et al. in 2002 [21] recruiting both students and teachers found that only 7/277 (2.5\%) of surveyed children achieved an excellent result, 57 (20.6\%) achieved a good result and 163(58.9\%) represented inadequate level of knowledge. Importantly, none of surveyed teachers achieved an excellent result. Parnell and collaborates [24] conducted a study to assess the attitude towards and knowledge of CPR among 494 high-school students 16 - 17-years of age in New Zealand. Poor theoretical knowledge (mean score $5.61 \pm 2.61$ out of a maximum score of 18 ) was recorded. Although there was no difference between male and female students, those who received previous FA training (70\%) significantly scored $6.04 \pm 2.56$-vs. $4.91 \pm 2.24$ knowledge sore for untrained counterparts.

From the academic standpoint, most FA courses are designed in such a way that they better suit people who are well-educated. Indeed, this is supported by several of the findings, e.g., the responses indicating that persons with a university education had been more apt to take action at crash sites and also had had most use of their FA skills. Perhaps, the courses should be altered so that they fit the needs of persons with different levels of education [17]. As a partial solution, several attempts are tried, worldwide, one of which is what was documented in Italy, where training course on FA have been designed for children aged 8 - 11 years in their last three courses at primary school. The course covers both theoretical and practical training, and the assessment of its impact revealed that it was successful in improving knowledge and skills of the students regarding FA. It was emphasized on the necessity for integration of the subject into the core curriculum of primary schools, extended to higher school levels, which could help in disseminating the culture of emergency care in the general population [25]. Earlier, in a study conducted in England, it was ascertained that in order to maximize the number of potential providers of CPR in the community, the program of basic life support (BLS) training should be included within the school curriculum [26]. In New Zealand, too where the resuscitation skills such as CPR are taught as an optional offering, a study to assess the impact of the program revealed a significant difference between those who chose the enrollment of the program and those who did not. The recommendation was that greater funding is needed for resuscitation/ FA learning and that the subject must become a compulsory rather than optional component of the school curriculum [27]. Also in Canada, where different models were tested for training students about FA, it was concluded that instituting a mandatory video-assisted CPR program in the junior students' system and in high schools and colleges throughout the world, would be a cost-effective way to train massive amounts of young people in CPR [28]. On the same line, not only the stress on teaching students FA is crucial but also the training of teachers, whose training was emphasized in Turkey, simultaneously. Doing so, it was found that the teachers did not have enough knowledge about first aid and it was recommended that training program on first aid targeting school teachers should be established and incorporated in the curriculum of the teachers' preparation [29]. In an interesting endeavor in Ireland to benefit from the basics of the "ABC for life" (airway-breathing-circulation) program which was designed to facilitate the wider dissemination of BLS skills in 
the population [30], a follow up assessment demonstrated that using this program for 10-12-year old children enables performing and retaining these vital skills, thanks to the use of a pyramidal teaching approach involving medical students and teachers. The lesson learnt is that previously trained teachers by medical students can teach BLS effectively to their primary school children, an experiment that could be extended to involve other school children in all stages. Similar studies concluded that the systematic solution for improvement of the knowledge of rules of giving FA should be adopted first educating teachers on FA skills, e.g., through senior medical students, who in turn would be in a position to educate and train their students on the same skills with a high degree of efficiency and a favorable outcome [31]. In parallel to school education, educating the public about FA and optimum actions in response to emergency especially in high risk populations and hazardous settings, e.g., throughout the media and public means of communication is worth the investment. In a country such as Cambodia where the risk of burns is a public health problem and an estimated 20,000 burns and 2000 related deaths occur annually, TV messages targeting the preventive measures and first aid procedures to help victims were broadcasted [32]. Assessing the impact of those messages revealed that they had a positive impact on the knowledge of the viewers, including youngsters especially when the messages were being delivered by physicians, who recommended that a televised burn prevention campaign could be an effective method to improve their knowledge, especially if it was endorsed by an authority figure.

In Saudi Arabia, the awareness of the public and risk groups of first aid and BLS has not been satisfactorily tackled. In particular, there is a scarcity of research, if any, to measure and evaluate secondary school students' FA knowledge and skills. Therefore this study would be undertaken to assess the awareness of Saudi students exemplified by Taif secondary school students regarding the administration of first aid and BLS measures. Factors affecting knowledge and attitudes of the target population regarding FA would be identified. Bridging this gap in knowledge, alongside with the fact that this population group has more exposure to situations that require FA knowledge, e.g., due to higher outdoor activities, not only helps them adopt a preventive behavior to emergency occurrences but share educating their families and peers and hence add a significant input to the efforts paid to alleviate the burden of emergency incidents in the students' Saudi community.

\section{Methodology}

This study was undertaken at male secondary school setting in central Taif city, western Kingdom of Saudi Arabia (KSA) province. Taif public school system in central Taif (zip code 21944 KSA) is divided into four educational districts, north, east, south and west. As of 2010, the number of registered secondary school students in central Taif was 11,218 students, 6662 boys in 16 schools, and 4558 girls in 13 schools. The KSA public school education system is based on separated "boys" and "girls" schooling on the KSA jurisdiction. According to the study design, only secondary school "male" students (accounts more than 5\% of central Taif secondary school population) with age range between 15 and 19 years would be sampled for the study. [Sampling size (n) calculation was based on assuming a 95\% confidence interval (CI) with a degree of precision $5 \%$ of first aid knowledge level at $35 \%$, yielding $n=349$, raised up to 420 to compensate for uncompleted questionnaires, drop-out or other events leading to exclusion from the study]. The general secondary education in Taif, as in Saudi Arabia encompasses four grades: first, second, third, and fourth (equivalent to K9-12). As of 2012, this study year, each secondary school had 416 students on average; each school had an average of 104 students in each grade and an average of 4 classrooms per grade. The average capacity of a classroom was 26 students, all grades. A cluster of 16 classrooms was randomly selected from boy schools, whereas one classroom was selected from each grade of one school which had been randomly selected from each district. A total of 420 students were invited to take part in the survey to measure their knowledge, attitude and skills of FA aid and BLS.

A predesigned instrument validated in Arabic language was used to collect the required study data. (In developing the questionnaire, the investigators tended to first examine published studies of similar topics. However, there was no available complete "standard questionnaires" that can be used in the current study. Therefore, the questionnaire meant to address different items from the literature review. The proposed questionnaire was then reviewed by a panel of a community and family medicine experts and its face, construct, criterion, and content validity all evaluated until fully validated instrument has become on hand). The questionnaires consisted of 37 questions in 6 scales, including a) demographic criteria, e.g., age, parents' level of education, economic status as expressed by monthly income in Saudi Riyals (SR), (exchange rate 1SR $=\$ 2.7$ ) of family members residing at the same address from all sources, b) first aid and BLS level and quality of knowledge, e.g., definitions, basic 
physiological measurements, FA kit content (bandages, gloves, others), with a subscale on sources of information on FA whether books, articles, television, internet, c) awareness of the first aid capabilities at school, d) first aid and BLS practice and skills, e.g., dealing with an bodily injury, bleeding, chocking, e) attitude to FA and willingness to provide assistance in emergency situations, e.g., arrest, road traffic accidents (RTAs), and f) first aid training and FA procedures. Other than being a male secondary school student and a resident of Taif, no student would be excluded from the study. However in order to be included in the analysis, only returned questionnaires with $80 \%$ or more valid answers would be entered. In preparation for the study, a pilot administration had been conducted to assess the questionnaire's test-retest reliability. Fort-two secondary students from Taif central schooling system were given the questionnaire to respond to (response-a). The same questionnaire was re-administered by the same group one week later (response-b). A panel of juries (four public health and family medicine specialists) was selected to judge the responses. Test-retest reliability of the pilot questionnaires was calculated to assess the temporal stability of the utilized questionnaire items, using Spearman rho. Obtained correlation coefficients for each pair of items (response-A and response-B) were all significant on all correlations $(p<0.05)$ and reflecting moderate-strong correlation ranging between $0.67-0.93$. (Examples are as follows: FA box content: $r h o=0.83, p<0.05$, FA definition: $r h o=0.67, p<0.05$, pulse rate $r h o=0.78, p<0.05$, providing assistance to injured person $r h o=0.69, p<0.05 \mathrm{y}$, handling bleeding: $r h o=0.71, p<0.05$, handling checking $r h o=0.68, p<0.05$ ). Further, an acceptable-strong reliability evidence for the questionnaire's items was found: reliability alphas 0.78 for FA knowledge, 0.83 for attitude, 0.76 for practice, and 0.91 for training scales. Modifications of the questionnaire were done based on the pilot testing results. The questionnaire takes 25 - 30 minutes to complete. A clearance was obtained from the research and ethics committee of the department of education in Taif before the study. Onsite, each participant was informed about the aim of the study prior to the completion of questionnaire. It was made clear that participation was voluntary. We have also stressed the anonymity and confidentiality of any collected information, and that only generic outcome data might be disseminated in scientific settings. A verbal consent from each participant was considered a personal permission to participate in the study. A questionnaire scoring was based on the following rules: items with "yes /no/to some extent" answers are given "2" scores for "yes" "0" score for "no" and "1" for "to some extent". The same scoring system was given to items with "yes", "no", and "do not know" options. According to this system, the maximum score was 35. Generally, students who score less than 21 out of $35(<60 \%)$ on the administered questionnaire were considered "poor", those who scored between 22 and 28 (60\% - 80\%) were considered "fair", and those who scored 28 or more $(\geq 80 \%)$ were considered "good" on FA knowledge and skills. However, following the cross-sectional survey, students were split into 2 groups; those with tendency for poor-fair knowledge ( $<70 \%$ positive answers) and those with tendency for more favorable knowledge ( $\geq 70 \%$ positive answers). Particular variables that contribute to the lower level of poor FA knowledge were studied among those nested two groups. (This approach aimed to provide information on factors of particularly higher risk potential upon the students' level of knowledge). Collected data were verified, variables coded and entered to a Microsoft (MS) program with adequate backup. Both categorical variables (i.e., closed-ended questions offering fixed responses), and continuous variables (open ended questions the answers to which require quantities) were handled. Descriptive statistics, e.g., numbers, proportions, mean \pm standard deviation (SD), all were displayed, as appropriate. Analytically, statistical techniques were used, as appropriate. For the association between categorical variables, e.g., the influence of previous FA training on the level of knowledge of first aid and BLS among participants could be measured using the Chi square $\left(\chi^{2}\right)$ test of independence, or Fisher's exact alternate, where appropriate. In the analysis, the study population sample may often be stratified by age groups as less than 17-and more or equal to 17 years of age. The "Statistical Package for Social Sciences" (SPSS) software for Microsoft-version20 was used for the analysis. All tests were conducted at level of significance $\alpha=0.05$; results with $p$-values < 0.05 will be considered statistically significant.

\section{Results}

Out of 420 questionnaires distributed, 360 questionnaires submitted valid responses ( $\geq 80 \%$ valid responses to the questionnaire items), making a response rate of $85.7 \%$. Three main compartments are addressed in the results section: demographic findings, knowledge of respondents about first aid in association with the FA training status and other characteristics, and the source of first aid information as was addressed by the students. Table 1 displays the distribution of the study group by the demographic and socioeconomic traits of interest. Almost two 
Table 1. Socio-demographic characteristics of the students $(n=360)$.

\begin{tabular}{|c|c|c|c|}
\hline & Demographic characteristics & Number & $\%$ \\
\hline \multirow{4}{*}{ Age } & $<17$ years & 220 & \\
\hline & $\geq 17$ years & 140 & 61.1 \\
\hline & Mean \pm SD & $17.24 \pm 1.21$ & 38.9 \\
\hline & Range & 15 - 22 years & \\
\hline \multirow{2}{*}{ Nationality } & Saudi & 266 & 73.9 \\
\hline & Non-Saudi & 94 & 26.1 \\
\hline \multirow{2}{*}{ Father's education } & $<$ Intermediate & 158 & 43.9 \\
\hline & Intermediate or higher & 202 & 56.1 \\
\hline \multirow{2}{*}{ Mother's education } & $<$ Intermediate & 199 & 55.3 \\
\hline & Intermediate or higher & 161 & 44.7 \\
\hline \multirow{3}{*}{ Family income (SR) } & $<5000$ & 119 & 33.1 \\
\hline & $5000-<10,000$ & 160 & 44.4 \\
\hline & $\geq 10,000$ & 81 & 22.5 \\
\hline
\end{tabular}

thirds of the students aged less than 17 years with mean \pm SD $=17.24 \pm 1.21$ years, and the majority (73.9\%) were Saudis.

More than half of the students' parents (55.3\%) had a higher than intermediate qualification. One third of the students (33.1\%) came from families with monthly income less than SR 5,000, and only 22.5\% of students came families with monthly income $\geq$ SR 10,000 (Table 1).

Table 2 demonstrates that as little as 49 (13.6\%) students had ever attended previous training courses in first aid. Also, 93 (25.6\%) of surveyed students indicated that there is FA group in their schools.

Table 3 describes the knowledge of the students about some items of the basic information in FA, given their training status. It shows that a significantly higher frequency among the previously trained students (34.7\%) than the untrained students $(20.3 \%)$ of correctly defining first aid $\left[\chi^{2}(\mathrm{df}=1)=5.1, p=0.024\right]$. Also, it was found that almost all the trained students (98\%) correctly know the contents of the first aid box as opposed to $86.2 \%$ of the untrained, and this difference is statistically significant $\left[\chi^{2}(\mathrm{df} 1)=5.48, p<0.024\right]$. The overwhelming majority of the trained students (95.9\%) significantly know the Red Crescent (the Red Cross equivalent working in Saudi Arabia) telephone number, compared to $75.6 \%$ of the untrained student group $\left[\chi^{2}(\mathrm{df} 1)=10.33 p<0.001\right.$ ] When asked about the vital signs rates it was observed that the frequency of the trained students, e.g., who know the normal pulse rate in adults almost doubled that among untrained students (34.7\% vs. $17 \%),\left[\chi^{2}(\mathrm{df} 1)=8.42\right.$, $p<0.05]$. Further, $39.4 \%$ of trained students correctly responded to inquiring about normal blood pressure (BP) in adults compared to only $8.4 \%$ of the untrained $\left[\chi^{2}(\mathrm{df} 1)=35.8, p<0.001\right]$ (Table 3 ).

Meanwhile, less than half of students (43.6\%) pointed out that there are FA boxes in their school. Generally, the minority of the students (21.4\%) indicated that they have adequate knowledge about first aid.

Generally, the majority of the FA-trained students (89.8\%) significantly had the perception that they know how to deal with critical cases compared to $55.9 \%$ of untrained peers $\left[\chi^{2}(\mathrm{df} 1)=20.3, p<0.001\right]$ (Table 4 ). Also, it was observed that a significantly higher frequency of the trained students $(46.9 \%)$ than the untrained ones $(19 \%)$ knew how to measure pulse rate $\left[\chi^{2}(\mathrm{df} 1)=18.82, p<0.001\right]$. Noted too was a significantly higher frequency $(38.8 \%)$ of the trained than the untrained students $(15.1 \%)$ in knowing how to measure BP $\left[\chi^{2}(\mathrm{df} 1)=\right.$ 15.83, $p<0.001]$.

Particularly $83.7 \%$ of trained subjects reported familiarity with dealing with bleeding incidents vs. 58.2\% untrained subjects who did not know how to do so $\left[\chi^{2}(\mathrm{df} 1)=11.62, p=0.04\right]$. Likewise, $81.6 \%$ of participants reported positive response to asking about dealing with an injured person compared to $67.2 \%\left[\chi^{2}(\mathrm{df} 1)=4.13, p=\right.$ 0.04]. Dealing with chocking was among the FA knowledge level areas where previous training on first aid had a positive influence upon [59.2\% of trained had sound choking knowledge, 36.6 did not, $\chi^{2}(\mathrm{df} 1)=9.04, p=$ 0.003]. Nevertheless, it was noticed that there were no significant difference between the trained and untrained students as regards their knowledge about dealing with epistaxis, cotton use in wound, dealing with heart attack, dealing with diabetic patients and dealing with cases in RTAs (Chi-square tests and $p>0.05$ for all those analyses] (Table 4).

Table 5 describes the variation in level of FA knowledge score according to the factors that most likely af- 
Table 2. Training status of students and availability of first aid resources in their schools.

\begin{tabular}{ccc}
\hline Variables & Number & $\%$ \\
\hline Ever attending training in first aid & & 13.6 \\
Yes & 39 & 86.4 \\
No & & 25.8 \\
Presence of first aid group & 93 & 74.2 \\
Yes & 267 & 43.6 \\
No or do not know & & 56.4 \\
presence of first aid box & 157 & 21.4 \\
Yes & 203 & 78.6 \\
No & & 77 \\
Yevel of knowledge is enough & 283 & \\
No/To some extent &
\end{tabular}

Table 3. Students' knowledge of the of basic first aid information In relation with their training status.

\begin{tabular}{|c|c|c|c|c|c|}
\hline \multirow{2}{*}{\multicolumn{2}{|c|}{$\begin{array}{l}\text { Basic information } \\
\text { about first aid }\end{array}$}} & \multicolumn{2}{|c|}{ Training status } & \multirow{3}{*}{$\begin{array}{c}\text { Test statistic } \\
\chi^{2}(\mathrm{df} 1)=5.104\end{array}$} & \multirow{3}{*}{$\begin{array}{l}\text { P value } \\
0.024\end{array}$} \\
\hline & & \multirow{2}{*}{$\begin{array}{c}\text { Trained }(\mathrm{n}=49) \\
\text { N (\%) } \\
17(34.7 \%) \\
32(65.3 \%)\end{array}$} & \multirow{2}{*}{$\begin{array}{c}\text { Not trained }(\mathrm{n}=311) \\
\text { N }(\%) \\
63(20.3 \%) \\
248(79.7 \%)\end{array}$} & & \\
\hline Definition of first aid & Correct Incorrect & & & & \\
\hline Content of first aid box & Correct Incorrect & $\begin{array}{c}48(98.0) \\
1(2.0)\end{array}$ & $\begin{array}{c}268(86.2) \\
43(13.8)\end{array}$ & $\chi^{2}(\mathrm{df} 1)=5.48$ & 0.020 \\
\hline Red Crescent number & $\begin{array}{l}\text { Yes } \\
\text { No }\end{array}$ & $\begin{array}{c}47(95.9) \\
2(4.1)\end{array}$ & $\begin{array}{c}235(75.6) \\
76(24.4)\end{array}$ & $\chi^{2}(\operatorname{df} 1)=10.33$ & $<0.001$ \\
\hline $\begin{array}{l}\text { Normal pulse } \\
\text { rate in adults }\end{array}$ & Correct Incorrect & $\begin{array}{l}17(34.7) \\
32(65.3)\end{array}$ & $\begin{array}{c}53(17.0) \\
258(83.0)\end{array}$ & $\chi^{2}(\mathrm{df} 1)=8.42$ & 0.004 \\
\hline $\begin{array}{l}\text { Normal blood } \\
\text { pressure in adults }\end{array}$ & Correct Incorrect & $\begin{array}{l}19(39.4) \\
30(60.6)\end{array}$ & $\begin{array}{c}26(8.4) \\
285(91.6)\end{array}$ & $\chi^{2}(\mathrm{df} 1)=35.8$ & $<0.001$ \\
\hline
\end{tabular}

Table 4. Knowledge of students about the practice of first aid according to their training status.

\begin{tabular}{|c|c|c|c|c|c|}
\hline \multirow{2}{*}{\multicolumn{2}{|c|}{$\begin{array}{l}\text { Knowledge regarding } \\
\text { Practice of first aid }\end{array}$}} & \multicolumn{2}{|c|}{ Training status } & \multirow[b]{2}{*}{ Test statistic } & \multirow[b]{2}{*}{ p-value } \\
\hline & & \multirow{2}{*}{$\begin{array}{c}\text { Trained }(\mathrm{n}=49) \\
\mathrm{N}(\%) \\
44(89.8) \\
5(10.2)\end{array}$} & \multirow{2}{*}{$\begin{array}{c}\text { Not trained }(\mathrm{n}=311) \\
\mathrm{N}(\%) \\
174(55.9) \\
137(44.1)\end{array}$} & & \\
\hline Dealing with critical cases & $\begin{array}{l}\text { Yes } \\
\text { No }\end{array}$ & & & $\chi^{2}(\mathrm{df} 1)=20.3$ & $<0.001$ \\
\hline Measuring pulse rate & $\begin{array}{l}\text { Yes } \\
\text { No }\end{array}$ & $\begin{array}{l}23(46.9) \\
26(53.1)\end{array}$ & $\begin{array}{c}59(19.0) \\
252(81.0)\end{array}$ & $\chi^{2}(\mathrm{df} 1)=18.82$ & $<0.001$ \\
\hline Measuring BP & $\begin{array}{l}\text { Yes } \\
\text { No }\end{array}$ & $\begin{array}{l}19(38.8) \\
30(61.2)\end{array}$ & $\begin{array}{c}47(15.1) \\
264(84.9)\end{array}$ & $\chi^{2}(\mathrm{df} 1)=15.83$ & $<0.001$ \\
\hline Dealing in cases of bleeding & $\begin{array}{c}\text { Correct } \\
\text { Incorrect }\end{array}$ & $\begin{array}{l}41(83.7) \\
8(16.3)\end{array}$ & $\begin{array}{l}181(58.2) \\
130(41.8)\end{array}$ & $\chi^{2}(\mathrm{df} 1)=11.62$ & $<0.001$ \\
\hline Dealing with injured person & $\begin{array}{l}\text { Correct } \\
\text { Incorrect }\end{array}$ & $\begin{array}{l}40(81.6) \\
9(18.4)\end{array}$ & $\begin{array}{l}209(67.2) \\
102(32.8)\end{array}$ & $\chi^{2}(\mathrm{df} 1)=4.13$ & 0.04 \\
\hline Dealing with epistaxis & $\begin{array}{c}\text { Correct } \\
\text { Incorrect }\end{array}$ & $\begin{array}{l}16(32.7) \\
33(67.3)\end{array}$ & $\begin{array}{c}84(27.3) \\
224(72.7)\end{array}$ & $\chi^{2}(\mathrm{df} 1)=0.61$ & 0.44 \\
\hline Deal in cases of chocking & $\begin{array}{c}\text { Correct } \\
\text { Incorrect }\end{array}$ & $\begin{array}{l}29(59.2) \\
20(40.8)\end{array}$ & $\begin{array}{l}113(36.6) \\
196(63.4)\end{array}$ & $\chi^{2}(\mathrm{df} 1)=9.04$ & 0.003 \\
\hline Cotton use in wound & $\begin{array}{c}\text { Correct } \\
\text { Incorrect }\end{array}$ & $\begin{array}{l}14(28.6) \\
35(71.4)\end{array}$ & $\begin{array}{l}115(37.0) \\
196(63.0)\end{array}$ & $\chi^{2}(\mathrm{df} 1)=1.30$ & 0.25 \\
\hline Dealing with heart attack & $\begin{array}{c}\text { Correct } \\
\text { Incorrect }\end{array}$ & $\begin{array}{l}37(75.5) \\
12(24.5)\end{array}$ & $\begin{array}{l}205(65.9) \\
106(34.1)\end{array}$ & $\chi^{2}(\mathrm{df} 1)=1.77$ & 0.18 \\
\hline Dealing with diabetic person & $\begin{array}{c}\text { Correct } \\
\text { Incorrect }\end{array}$ & $\begin{array}{c}43(87.8) \\
6(12.2)\end{array}$ & $\begin{array}{c}235(75.6) \\
76(24.4)\end{array}$ & $\chi^{2}(\mathrm{df} 1)=3.58$ & 0.059 \\
\hline Dealing with RTAs & $\begin{array}{c}\text { Correct } \\
\text { Incorrect }\end{array}$ & $\begin{array}{l}32(65.3) \\
17(34.7)\end{array}$ & $\begin{array}{c}225(72.3) \\
86(27.7)\end{array}$ & $\chi^{2}(\mathrm{df} 1)=1.03$ & 0.31 \\
\hline
\end{tabular}


Table 5. Bivariate analysis of the factors likely affecting level of knowledge of the students.

\begin{tabular}{|c|c|c|c|c|}
\hline \multirow[b]{2}{*}{ Characteristics of the students } & \multicolumn{2}{|c|}{ Knowledge score } & \multirow[b]{2}{*}{ Test statistic } & \multirow[b]{2}{*}{$p$-value } \\
\hline & $\begin{array}{l}<70 \% \\
\text { n (\%) }\end{array}$ & $\begin{array}{l}\geq 70 \% \\
\text { n (\%) }\end{array}$ & & \\
\hline $\begin{array}{l}\text { Training } \\
\text { Yes } \\
\text { No }\end{array}$ & $\begin{array}{c}10(20.4) \\
144(46.3)\end{array}$ & $\begin{array}{c}39(79.6) \\
167(53.7)\end{array}$ & $\chi^{2}(\mathrm{df} 1)=11.60$ & $<0.001$ \\
\hline $\begin{array}{l}\text { Age (Year) } \\
\quad<17 \\
\quad \geq 17\end{array}$ & $\begin{array}{l}83(37.7) \\
71(50.7)\end{array}$ & $\begin{array}{c}137(62.3) \\
69(49.3)\end{array}$ & $\chi^{2}(\mathrm{df} 1)=5.90$ & 0.02 \\
\hline $\begin{array}{l}\text { Nationality } \\
\text { Saudi } \\
\text { Non-Saudi }\end{array}$ & $\begin{array}{c}112(42.1) \\
42(44.7)\end{array}$ & $\begin{array}{c}154(57.9) \\
52(55.3)\end{array}$ & $\chi^{2}(\mathrm{df} 1)=0.19$ & 0.66 \\
\hline 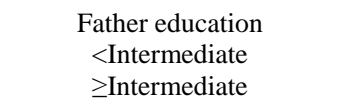 & $\begin{array}{l}67(42.4) \\
87(43.1)\end{array}$ & $\begin{array}{c}91(57.6) \\
115(56.9)\end{array}$ & 0.02 & 0.90 \\
\hline $\begin{array}{l}\text { Mother education } \\
<\text { Intermediate } \\
\text { >Intermediate }\end{array}$ & $\begin{array}{l}94(47.2) \\
60(37.3)\end{array}$ & $\begin{array}{l}105(52.8) \\
101(62.7)\end{array}$ & $\chi^{2}(\mathrm{df} 1)=3.61$ & 0.06 \\
\hline $\begin{array}{c}\text { House } \\
\text { Owned } \\
\text { Rent }\end{array}$ & $\begin{array}{l}67(50.0) \\
87(38.5)\end{array}$ & $\begin{array}{c}67(50.5) \\
139(61.5)\end{array}$ & $\chi^{2}(\mathrm{df} 1)=4.55$ & 0.03 \\
\hline $\begin{array}{c}\text { Income } \\
<5000 \\
5000-10,000 \\
>10,000\end{array}$ & $\begin{array}{l}42(35.3) \\
70(43.8) \\
40(51.9)\end{array}$ & $\begin{array}{l}77(64.7) \\
90(56.2) \\
39(48.1)\end{array}$ & $\chi^{2}(\mathrm{df} 2)=5.51$ & 0.06 \\
\hline
\end{tabular}

fecting the students' FA knowledge and performance. Two score levels are examined: lower score equivalent to $<70 \%$ and higher score equivalent to $\geq 70 \%$. Expectedly, a higher proportion of FA-trained students (79.6\%) were among the higher score category in comparison to $20.4 \%$ trained peers who were among the $<70 \%$ score category $\left[\chi^{2}(\mathrm{df} 1)=11.60, p<0.001\right]$ (Table 5).

Meanwhile, younger students ( $<17$ years) generally had a higher score $(62.3 \%)$, in comparison to older colleagues $(49.3 \%)\left[\chi^{2}(\mathrm{df} 1)=5.90, p=0.02\right]$. Also, it was remarked that students who are living in rented houses were among the group which achieved a higher score (61.5\%) than those who are living in owned houses $(50.5 \%)\left[\chi^{2}(\mathrm{df} 1)=4.55, p=0.03\right]$. Neither the nationality nor the parents' education or the family income had a significant effect on the FA-knowledge score of the students. Knowledge-wise too, the preliminary data analysis revealed that the main sources of information about FA as indicated by the students was the TV marked by more than half of the students (56.4\%), followed by the parents (43.4\%), books (39.2\%) and teachers (33.6\%). The least likely source of information was the brochures (15\%).

When they were asked about the preferable sources of information about FA, the majority of the students (73.6\%) replied that they prefer to get their information from physicians followed by nurses (19.4\%), TV and books (13.9\%). The least preferable source for information about first aid was the newspapers (11.1\%). Regarding the presence of FA materials in the school curriculum, $37.2 \%$ of the students pointed out that there was such materials in their school curriculum and as much as $62.8 \%$ marked otherwise. In response to items about suggestions to improve their knowledge about FA, two thirds of the students (66.1\%) suggested the need for presence of nurses in their schools. Furthermore, the majority of the students (81.1\%) pointed out to the necessity of community education in the field of first aid. More than one half of the students (56.1\%) thought that adding first aid in the curriculum would improve their knowledge.

To summarize important predictors of the students' FA knowledge, a multivariate regression model including significant factors affecting the outcome variable, i.e., level of knowledge of the students, has been constructed (Table 6). Significantly entered predictors included 1) first aid training which was the chief predictor for improving the knowledge of the students [regression coefficient $(\beta)=1.21$, standard error $(\mathrm{SE})=0.38,95 \% \mathrm{CI} 1.60$ 7.06], 2) the presence of first aid group in the schools $(\beta=0.82$, $\mathrm{SE}=0.38,95 \%$ CI $1.34-3.96)$, 3) housing 
Table 6. Multivariate logistic regression predictors of the level of knowledge of the students about first aid.

\begin{tabular}{ccccc}
\hline Factors in the model & $\beta(\mathrm{SE})$ & $p$-value & OR & $95 \%$ CI \\
\hline Training & $1.21(0.38)$ & 0.001 & 3.35 & $1.60-7.06$ \\
First aid group & $0.82(0.27)$ & 0.002 & 2.28 & $1.34-3.95$ \\
House & $0.50(0.23)$ & 0.031 & 1.65 & $1.05-2.60$ \\
Age & $0.38(0.23)$ & 0.095 & 1.47 & $0.94-2.30$ \\
\hline
\end{tabular}

which was the least effective predictor in the model, so that ownership of the house had a regression coefficient of $0.5 \pm$ SE 0.23 , 95\% CI 1.05 - 2.6 (Table 6). [NB. The 95\% CI of each predictor's coefficient contains a range of the odds of the likelihood to report a change in the outcome as a result of a unit change in the corresponding input predictor. For instance, FA -trained students are 1.6 - 7.06 times prone for a positive 1.21 change in FA knowledge. In order to obtain the exact odds ratio (OR) for such relationship not just the range, OR simply = exponent $\beta$ training $=\mathrm{e}^{1.21}=3.35$. This means that FA-trained subjects are 3.35 times more prone to report an improvement in their level of FA knowledge (notice that 3.35 lies in the range of the 95\%CI 1.60 - 7.06). (The same algebraic technique could be applied to conclude the exact ORs for other predictors. In the model, too, there was a significantly strong correlation between the predictors and the outcome variable "improvement of FA knowledge" [correlation coefficient $(r)=0.83, p=0.02$ ]. Further, $69 \%$ of the change in the outcome variable could be explained by the model $\left(r^{2}=0.69\right)$.

\section{Discussion}

This study comprised a group of secondary school students in Saudi Arabia. Their age ranged between 15 - 19 years. Almost half of the students' parents had more than intermediate education and almost one third of them were in families with less than 5000 SAR of a monthly income. The students' interest in first aid as recognized by this work has been found modest. For instance, a few students have previously attended first aid training courses, and awareness of the presence of first aid group in the schools was reported by only one fourth of the study population. Information that were significantly known by previously trained students more than untrained students include definition of FA, content of FA box, Red Crescent number, normal pulse rate and normal adult BP range. Well, it may sound logic to depict such a higher proportion of correct BP information answers (39.4\%) in FA-trained students compared to only $8.4 \%$ correct responses about this basic physiological measurement in the untrained; however, in a community with high prevalence of hypertension like Saudi Arabia [33], we expected to find a higher proportion of individuals regardless their FA education status who show better awareness of such basic BP information. Apparently, the FA climate in Saudi schools implies that FA does not gain the due attention of the local school network management, yet. And this is also indicated by a number of the educational components, including the students, and probably the teachers and other stakeholders who are not adequately prepared for dealing with FA and BLS on a firm basis. This impression would be further augmented by the broader recognition that FA learning is not mandatory in the Saudi education system, until the time of this report, and is only accessed as a voluntary or an extra-curricular student activity. Also perhaps this explains why only about one third of the students recognize the presence of any FA materials in their learning program. Regardless the presence or absence of FA and BLS on the schools' core curriculum, the analysis conducted by us frequently reveals a multitude of favorable impacts of FA training upon FA measures among the studied student population. For instance, the level of FA familiarity and skills handling vital tasks such as dealing with critical cases or measuring pulse and BP was significantly more prominent in the FA-trained students than the untrained counterparts. The same trend was observed in dealing with bleeding incidents, injured persons and chocking events. In contrast, some other important information such as dealing with epistaxis, heart attacks, diabetic patients or rescue actions to RTA victims, all were equivalently unsatisfactory in both trained and untrained students, perhaps a repercussion of the lack of the FA training programs in explaining these issues. Such equivocal degree of success and failure in FA attention of schools in KSA may emphasize the impression that a widespread and efficient FA learning in the country's education arena has not yet reached its desirable standard.

Despite the view of international resuscitation councils that the teaching of resuscitation in schools should be regarded as a primary educational strategy to achieve widespread learning of CPR [34], the current study de- 
monstrates that as little as $13.6 \%$ of students attend training in FA. The humble level of FA-preparedness among our students cannot be blamed utterly on the students' part; most of them (78.6\%) do admit that they have inadequate knowledge about FA, nonetheless most of them probably would like to learn FA and related measures on sound regular basis [19], and all they need to bridge this gap is to receive the due support from the school, particularly envisioning FA and BLS as a core education requirement, same as other basic science, math or language courses. In a report on the optimum design and delivery of FA and common health emergency measures courses, it was recorded that seven out of ten students would not know what to do if someone they knew was hurt, yet the majority said they would like to learn FA [35].

Our search reveals that the unsatisfactory FA preparedness is not exclusive to the Saudi student community, whereas in Lublin, Poland, 67\% of the students admitted that their knowledge and skills are insufficient to conduct FA and that they wished they would have the opportunity to improve this very part of their learning objectives [19]. In Cambodia, too, the assessment of knowledge of the students revealed significant inadequacies in knowledge about burn prevention and first aid in general [32]. In agreement with a body of research on the FA knowledge inadequacy between similar population stratum, our study definitely shows that the level of knowledge of the secondary-school students was significantly higher among those who had attended FA training courses, as opposed to untrained peers. For insistence, Sosada, et al. [21] reported that their students who had a diving license (necessitates completion of BLS training), had significantly higher level of FA knowledge in comparison to those who did not have the opportunity to attend BLS training. An interventional study from Norway also compared between subject classes which participated in a FA-training program and control classes which resumed normal education without supportive FA-training found a significant differences in many of the correlates to self-efficacy, skills and attitudes toward giving and learning first aid [36]. The non-significant difference in knowledge of our trained- and untrained-students regarding some items e.g., heart attacks, diabetic patients and RTAs may imply that students tend to gain FA orientation through schools, if any, as an extra-curricular activity.

Televised material as well as the parents, is the chief source of information about first aid in this study's population. An almost similar finding was reported in a study where it was reported that televised campaign is an effective method to improve viewers' FA knowledge including youngsters. In a survey study conducted to assess the impact of televised messages targeting FA and BLS, it was revealed that these messages are trustable and could have an impact on young viewers when it is provided by an authority figure such as a physician, teacher, parent, or the Ministry of Health [37]. In our study, the most preferable source of information about first aid was also thought to be physicians. These findings further support the fact that visual learning is more comprehensive and effective, especially in the young age groups, and students in this age can retain more knowledge through visual methods more than lecturing and only auditory unattractive methods [19] [29]. It is highly recommended, thereby to focus future training activities using modern visual methods of learning. Moreover, students are more convinced when they get their information; learn directly from physicians [37], as a most trustful source of medical information, especially FA, and almost as preferably from nursing staff. This conceptualization is worth consideration in designing future training programs; make them shared by physicians beside other qualified medical staff members. Eventually, concern should be directed to reviewing school curricula to assess the magnitude of the body of FA information included. Policymakers in the local and national Saudi departments of education should include more information covering FA required data, especially in the later stages of education, i.e., intermediate and secondary schools. Optimistically, the majority of our students agree on the need to disseminate FA awareness in the whole community. Disproportionately, only more than half of our students agree to administer FA in school curriculum. The paradox here that only half (56.6\%) of our students see that including FA in the curriculum (an endeavour tested in many countries and proved effective in increasing the awareness and self confidence of the students about their abilities in conducting FA when needed), would ever improve their FA knowledge may well be attributed to the impression that Saudi students have been subject to inheriting FA learning the shape it is handled in school till present as an optional (less important) area of inquiry, e.g., compared to core subjects (e.g., math or science). And even if presented, an FA class would be stuffed with didactic material that lacks attraction, fun and demonstration, and hence perceived as being of a little use. As such, many students may doubt the value of adding current FA teaching in the curriculum. Particularly dealing with such cumbersome scientific topics like medial emergency may not be that appealing to youngsters especially that the task embraces large volume of responsibility and demands a high degree of confidence not all students are able to provide unless equipped with. Needless to say, relating proper and practical 
information on FA and BLS would be an invaluable opportunity for a tangible improvement of the outcome of acute health emergencies in the Saudi community, at least ensuring supporting people's threatened life until professional assistance shows up. Nonetheless, the mainstay of the acceptance and success of such training endeavor involves the set up and the approach we use to endorse, stressing the need to "gift-wrap" it in an attractive framework to catch the students' utmost attention. In Turkey [29], most participants in the FA and BLS training course which adopted attractive practical approach as being facilitated by academic supervisors considered the program most successful and effective.

The present work adds important data about first aid preparedness and potentials among an important sector of the Saudi community, namely secondary school children that can be used to improve the outcome of health emergency problems in the community. Given that out of 26.9 million Saudi population; $46 \%$ is under the age of 21 [37] (19.4\% 15 - 24 years of age, 27.6\% 0 - 14 years), including secondary-school age children, equipping such population with proper FA capabilities and allowing them to proactively participate in this field of health demands is worth the investment. Due to the administrative limitation that boys and girls schools are strictly separated in Saudi Arabia, and probably the need to have allocated double amount of resources and time to cover up both sexes, only boys were accessible to us in this research. Based on the findings of this study, it is strongly recommended that an integrated plan including both theoretical and practical training using the "ABC" simplified program [30] in FA tailored to students should be included in the educational material of the secondary schools. Conducting a pilot endeavor of the feasibility of implementing the pyramidal training approach on FA starting by the medical students at the top of the pyramid through the teachers as the body of the pyramid and ending with the students as its base is worthwhile contemplation. Further researches are needed to assess the skills of the trained students on conducting the wide array FA including BLS, trauma, injury, and important systemic health emergencies. In parallel, emphasis should be put on the FA messages delivered through mass media, and make benefit of the physicians in this field as they, according to this study and other studies [38], are predominantly the most trustable for the students to provide these messages. Further, well-trained students who have graduated from such well-structured FA training programs may well be significant aide in transmitting the gained FA knowledge and skills to their student community, their families, and the entire population. In conclusion, maintaining and improving FA skills of secondary-school age children have a crucial effect in alleviating the consequences of medical emergencies suffered in Saudi Arabia, with an invaluable both public's health benefits and economic savings. Emphasizing and promoting for incorporating FA training in secondary-and also all age-Saudi school curricula is pivotal for enhancing the success potential of the present and future national emergency-control first-aid efforts.

\section{Congresses}

None.

\section{Funding}

Self-funded.

\section{Conflicts of Interest}

None.

\section{References}

[1] St. John Ambulance (2006) First Aid Training: First on the Scene. Student Reference Guide Activity Book. St. John Ambulance, 23-25.

[2] Ege, R. (1999) First Aid and Emergency in Accident, Disease and Injury 3rd Printing. Turkish Air Foundation Press, Ankara.

[3] Spinks, A.B., McClure, R.J., Bain, C. and Macpherson, A.K. (2006) Quantifying the Association between Physical Activity and Injury in Primary School-Aged Children. Pediatrics, 118, 43-50. http://dx.doi.org/10.1542/peds.2005-2275

[4] Lester, C.A., Weston, C.F., Donnelly, P.D., Assar, D. and Morgan, M.J. (1994) The Need for wider Dissemination of CPR Skills: Are Schools the Answer? Resuscitation, 28, 233-237. http://dx.doi.org/10.1016/0300-9572(94)90069-8 
[5] Davies, C.S., Colquhoun, M.C., Graham, S., Evans, T. and Chamberlain, D. (2002) Defibrillators in Public Places: The Introduction of a National Scheme for Public Access Defibrillation in England. Resuscitation, 52, 13-21. http://dx.doi.org/10.1016/S0300-9572(01)00439-7

[6] National Health Services, UK. First Aid. What Should I Keep in My First Aid Kit? http://www.nhs.uk/chq/pages/990.aspx?CategoryID=72\&SubCategoryID=725

[7] Baser, M. (2007) Evaluating First Aid Knowledge and Attitude of a Sample of Turkish Primary School Teachers. Journal of Emergency Nursing, 33, 428-432.

[8] Eisenburger, P. and Safar, P. (1999) Life Supporting First Aid Training of the Public-Review and Recommendations. Resuscitation, 41, 3-18. http://dx.doi.org/10.1016/S0300-9572(99)00034-9

[9] Afifi, R., Shata, S.Z., Raggal, A., Ayoub, H. and Qulali, A. (2015) Involvement of Male Youth into Accidents in Upper Egypt: Pattern and Risk Analysis. Health, 7, 965-975. http://dx.doi.org/10.4236/health.2015.78114

[10] Tursz, A. (1986) Epidemiological Studies of Accident Morbidity in Children and Young People. World Health Statistics Quarterly, 39, 257-267.

[11] Orzel, M.N. (1996) Injury Minimization Programme for Schools. Accident and Emergency Nursing, 4, 139-144. http://dx.doi.org/10.1016/S0965-2302(96)90061-2

[12] Pearn, J. (1994) The Earliest Days of First Aid. BMJ, 309, 1718-1720. http://dx.doi.org/10.1136/bmj.309.6970.1718

[13] Glendon, A.I. and McKenna, S.P. (1995) Using Accident Injury Data to Assess the Impact of Community First Aid Training. Public Health, 99, 98-109. http://dx.doi.org/10.1016/S0033-3506(85)80006-8

[14] Peterson, T.D., Noland, S., Russell, D.W. and Paradise, N.F. (1999) Bystander Trauma Care Training in Iowa. PreHospital Emergency Care, 3, 225-230. http://dx.doi.org/10.1080/10903129908958941

[15] Hussain, L.M. and Red Mound, A.D. (1997) Are Pre-Hospital Deaths from Accidental Injury Preventable? BMJ, 308, 1077-1080. http://dx.doi.org/10.1136/bmj.308.6936.1077

[16] Henriksson, M., Ostrom, M. and Eriksson, A. (2001) Preventability of Vehicle-Related Fatalities. Accidents Analysis and Prevention, 33, 467-475. http://dx.doi.org/10.1016/S0001-4575(00)00060-9

[17] Larsson, E.M., Mártensson, N.L. and Alexanderson, K.A. (2003) First-Aid Training and Bystander Actions at Traffic Crashes-A Population Study. Resuscitation, 17, 134-141.

[18] Shibata, K., Taniguchi, T., Yoshida, M. and Yamamoto, K. (2000) Obstacles to Bystander Cardiopulmonary Resuscitation in Japan. Resuscitation, 44, 187-193. http://dx.doi.org/10.1016/S0300-9572(00)00143-X

[19] Goniewicz, M., Chemperek, E. and Mikula, A. (2002) Attitude of Students of High Schools in Lublin towards the Problem of First Aid. Wiadomosci Lekarskie, 55, 679-685.

[20] Eisenberg, M.S. and Mengert, T.J. (2001) Cardiac Resuscitation. New England Journal of Medicine, 344, $1304-1313$. http://dx.doi.org/10.1056/nejm200104263441707

[21] Sosada, K., Zurawinski, W., Stepien, T., Makarska, J. and Myrcik, D. (2002) Evaluation of the Knowledge of Teachers and High School Students in Silesia on the Principles of First Aid. Wiadomosci Lekarskie, 55, 883-889.

[22] Uray, T., Lunzer, A., Ochsenhofer, A., Thanikkel, L., Zingerle, R., Lillie, P., et al. (2003) Feasibility of Life-Supporting First-Aid (LSFA) Training as a Mandatory Subject in Primary Schools. Resuscitation, 59, 211-220. http://dx.doi.org/10.1016/S0300-9572(03)00233-8

[23] Federal Emergency Management Agency (FEMA) A Whole Community Approach to Emergency Management: Principles, Themes, and Pathways for Action FDOC 104-008-1/December 2011. http://www.fema.gov/media-library-data/20130726-1813-25045-0649/whole community dec2011 2 .pdf

[24] Parnell, M.M., Pearson, J., Galletly, D.C. and Larsen, P.D. (2006) Knowledge of and Attitudes towards Resuscitation in New Zealand High-School Students. Emergency Medicine Journal, 23, 899-902. http://dx.doi.org/10.1136/emj.2006.041160

[25] Lubrano, R., Romero, S., Scoppi, P., Cocchi, G., Baroncini, S., Elli, M., et al. (2005) How to Become an under 11 Rescuer: A Practical Method to Teach First Aid to Primary Schoolchildren. Resuscitation, 64, 303-307. http://dx.doi.org/10.1016/j.resuscitation.2004.09.004

[26] Lewis, R.M., Fulstow, R. and Smith, G.B. (1997) The Teaching of Cardiopulmonary Resuscitation in Schools in Hampshire. Resuscitation, 35, 27-31. http://dx.doi.org/10.1016/S0300-9572(97)00027-0

[27] Lafferty, C., Larsen, P.D. and Galletly, D. (2003) Resuscitation Teaching in New Zealand Schools. New Zealand Medical Journal, 116, U582.

[28] Liberman, M., Golberg, N., Mulder, D. and Sampalis, J. (2000) Teaching Cardiopulmonary Resuscitation to CEGEP Students in Quebec-A Pilot Project. Resuscitation, 47, 249-257. http://dx.doi.org/10.1016/S0300-9572(00)00236-7

[29] Baser, M., Coban, S., Tasci, S., Sungur, G. and Bayat, M. (2007) Evaluating First-Aid Knowledge and Attitudes of a 
Sample of Turkish Primary School Teachers. Journal of Emergency Nursing, 33, 428-432. http://dx.doi.org/10.1016/j.jen.2006.11.003

[30] Toner, P., Connolly, M., Laverty, L., McGrath, P., Connolly, D. and McCluskey, D.R. (2009) Teaching Basic Life Support to School Children Using Medical Students and Teachers in a "Peer-Training" Model—Results of the "ABC for Life” Programme. Resuscitation, 75, 169-175. http://dx.doi.org/10.1016/j.resuscitation.2007.03.009

[31] Wisniewski, J. and Majewski, W.D. (2007) Assessment of Knowledge about First Aid among the Teachers of Chosen High Schools in the Western Pomerania Region. Annales Academiae Medicae Stetinensis, 53, 114-123.

[32] Hsiao, M., Tsai, B., Uk, P., Jo, H., Gomez, M., Gollogly, J.G., et al. (2007) "What Do Kids Know”: A Survey of 420 Grade 5 Students in Cambodia on Their Knowledge of Burn Prevention and First-Aid Treatment. Burns, 33, $347-351$. http://dx.doi.org/10.1016/j.burns.2006.08.002

[33] Al-Nozha, M.M., Abdullah, M., Arafah, M.R., Khalil, M.Z., Khan, N.B., Al-Mazrou, Y.Y., Al-Maatouq, M.A., Al-Marzouki, K., Al-Khadra, A., Nouh, M.S., Al-Harthi, S., Al-Shahid, M.S. and Al-Mobeireek, A. (2007) Hypertension in Saudi Arabia. Saudi Medical Journal, 28, 77-84.

[34] European Resuscitation Council (2000) Part 1: Introduction to the International Guidelines 2000 for CPR and ECC. Resuscitation, 46, 3-15. http://dx.doi.org/10.1016/S0300-9572(00)00269-0

[35] St. John Ambulance. Student First Aid Programme. http://www.sja.org.uk/sja/training-courses/school-student-training/student-first-aid-programme.aspx

[36] England, A., Roysamb, E., Smedslund, G. and Sogaard, A.J. (2002) Effects of First-Aid Training in Junior High Schools. Injury Control and Safety Promotion, 9, 99-106. http://dx.doi.org/10.1076/icsp.9.2.99.8702

[37] House, K.E. (2012) On Saudi Arabia: It’s People, Past, Religion, Fault Lines and Future. Vintage Books, New York, 221.

[38] Ltintas, K.H., Aslan, D., Yildiz, A.N., Subasi, N., Elcin, M., Odabasi, O., et al. (2005) The Evaluation of First Aid and Basic Life Support Training for the First Year University Students. The Tohoku Journal of Experimental Medicine, 205, 157-169. http://dx.doi.org/10.1620/tjem.205.157 